\title{
Avoiding Tacrolimus Underexposure and Overexposure with a Dosing Algorithm for Renal Transplant Recipients: A Single Arm Prospective Intervention Trial
}

\author{
Marith I. Francke ${ }^{1,2,3, *}$, Louise M. Andrews ${ }^{4,5}$, Hoang Lan Le ${ }^{4}$, Jacqueline van de Wetering ${ }^{1,2}$,
} Marian C. Clahsen-van Groningen ${ }^{2,6}$, Teun van Gelder ${ }^{7}$, Ron H. N. van Schaik ${ }^{8}$, Bronno van der Holt ${ }^{9}$, Brenda C. M. de Winter ${ }^{2,4}$ and Dennis A. Hesselink ${ }^{1,2}$

Bodyweight-based tacrolimus dosing followed by therapeutic drug monitoring is standard clinical care after renal transplantation. However, after transplantation, a meager $38 \%$ of patients are on target at first steady-state and it can take up to 3 weeks to reach the target tacrolimus predose concentration $\left(\mathbf{C}_{0}\right)$. Tacrolimus underexposure and overexposure is associated with an increased risk of rejection and drug-related toxicity, respectively. To minimize subtherapeutic and supratherapeutic tacrolimus exposure in the immediate post-transplant phase, a previously developed dosing algorithm to predict an individual's tacrolimus starting dose was tested prospectively. In this singlearm, prospective, therapeutic intervention trial, 60 de novo kidney transplant recipients received a tacrolimus starting dose based on a dosing algorithm instead of a standard, bodyweight-based dose. The algorithm included cytochrome P450 (CYP)3A4 and CYP3A5 genotype, body surface area, and age as covariates. The target tacrolimus $\mathrm{C}_{0}$, measured for the first time at day 3, was 7.5-12.5 ng/mL. Between February 23, 2019, and July 7, 2020, 60 patients were included. One patient was excluded because of a protocol violation. On day 3 post-transplantation, 34 of 59 patients (58\%, 90\% Cl 47-68\%) had a tacrolimus $\mathrm{C}_{0}$ within the therapeutic range. Markedly subtherapeutic $(<5.0 \mathrm{ng} / \mathrm{mL}) \mathrm{and}$ supratherapeutic (> $20 \mathrm{ng} / \mathrm{mL}$ ) tacrolimus concentrations were observed in $7 \%$ and $3 \%$ of the patients, respectively. Biopsy-proven acute rejection occurred in three patients (5\%). In conclusion, algorithm-based tacrolimus dosing leads to the achievement of the tacrolimus target $C_{0}$ in as many as $58 \%$ of the patients on day 3 after kidney transplantation.

Study Highlights

\section{WHAT IS THE CURRENT KNOWLEDGE ON THE TOPIC? \\ $\checkmark$ Renal transplant recipients are at risk for underexposure and overexposure to tacrolimus, due to its narrow therapeutic range and a large interpatient variability in its pharmacokinetics. \\ WHAT QUESTION DID THIS STUDY ADDRESS? \\ $\square$ Does the use of a starting dose algorithm for tacrolimus after renal transplantation minimize underexposure and overexpo- sure to tacrolimus in the early post-transplant phase? \\ WHAT DOES THIS STUDY ADD TO OUR KNOW-LEDGE? \\ $\square$ A dosing algorithm that includes age, body surface area, and $C Y P 3 A 4$ and $C Y P 3 A 5$ genotype, predicts an individual kidney}

transplant recipient's tacrolimus starting dose successfully in as many as $58 \%$ of patients.

HOW MIGHT THIS CHANGE CLINICAL PHARMACOLOGY OR TRANSLATIONAL SCIENCE?

$\checkmark$ The use of this tacrolimus dosing algorithm appears to outperform standard, bodyweight-based tacrolimus (start) dosing and has the potential to reduce tacrolimus exposure outside the target concentration range.

\footnotetext{
${ }^{1}$ Department of Internal Medicine, Division of Nephrology and Transplantation, Erasmus MC, University Medical Center Rotterdam, Rotterdam, The Netherlands; ${ }^{2}$ Rotterdam Transplant Group, Rotterdam, The Netherlands; ${ }^{3}$ Netherlands Institute for Health Sciences, Rotterdam, The Netherlands; ${ }^{4}$ Department of Hospital Pharmacy, Erasmus MC, University Medical Center Rotterdam, Rotterdam, The Netherlands; ${ }^{5}$ Department of Hospital Pharmacy, Meander Medical Center, Amersfoort, The Netherlands; ${ }^{6}$ Department of Pathology, Erasmus MC, University Medical Center Rotterdam, Rotterdam, The Netherlands; ${ }^{7}$ Department of Clinical Pharmacy and Toxicology, Leiden University Medical Center, Leiden, The Netherlands; ${ }^{8}$ Department of Clinical Chemistry, Erasmus MC, University Medical Center, Rotterdam, The Netherlands; ${ }^{9}$ Department of Hematology, Erasmus MC Cancer Institute, Rotterdam, The Netherlands. *Correspondence: Marith I. Francke (m.francke@erasmusmc.nl)
}

Received November 5, 2020; accepted December 21, 2020. doi:10.1002/cpt.2163 
Bodyweight-based tacrolimus dosing followed by dose titration based on whole-blood concentrations, a practice known as therapeutic drug monitoring (TDM), is standard clinical care after solid organ transplantation. ${ }^{1}$ According to the manufacturer's instructions, the tacrolimus starting dose should be $0.1-0.2 \mathrm{mg} / \mathrm{kg}$ bodyweight per day. ${ }^{2}$ However, the available evidence to support this strategy is thin. ${ }^{3}$ Bodyweight is a poor predictor of tacrolimus clearance and, as a result, many patients are overdosed or underdosed in the critical early post-transplant phase. ${ }^{4-6}$ Previous studies demonstrated that only $18.5-37.4 \%$ of renal transplant recipients were within the target tacrolimus predose concentration $\left(\mathrm{C}_{0}\right)$ range at first steady-state following initial bodyweightbased tacrolimus dosing. ${ }^{7-9}$ In addition, and despite the use of TDM, it can take up to 3 weeks before a transplant recipient is on target. ${ }^{7,9}$

Age, albumin, body surface area (BSA), comedication, cytochrome P450 (CYP) 3A genotype, ethnicity, and hematocrit influence tacrolimus pharmacokinetics. ${ }^{10-13}$ Population pharmacokinetic (popPK) models and dosing equations incorporating these variables have been developed to predict an individual transplant recipient's tacrolimus dose requirement. ${ }^{1,6,11,13-27}$ Clinical application of a popPK model to guide the tacrolimus (starting) dose may shorten the time to reach the target tacrolimus $\mathrm{C}_{0}$, minimize underexposure and overexposure, and improve clinical outcomes. $^{26,28}$

Few of these popPK models and dosing equations were successfully validated externally, ${ }^{6,15,24,29}$ and/or tested prospectively. ${ }^{18,30}$ Only one popPK model (which included CYP3A5 genotype and comedication) predicted the required tacrolimus dose successfully when applied in clinical practice. ${ }^{18}$ However, the latter popPK model cannot be used in White patients, because it was developed and tested in an Asian population. ${ }^{18}$

In the present prospective, single-arm, therapeutic intervention study, it was investigated whether a tacrolimus starting dose based on a previously developed dosing algorithm, ${ }^{11}$ leads to a sufficient percentage of patients being within the tacrolimus target $\mathrm{C}_{0}$ range on day 3 after transplantation, with respect to the percentage found in a historic control group of patients who received a standard tacrolimus starting dose based on bodyweight alone. $^{7}$

\section{PATIENTS AND METHODS}

This study was an investigator-initiated, prospective, single-arm, therapeutic intervention trial, in which kidney transplant recipients were prescribed a tacrolimus starting dose based on a dosing algorithm, ${ }^{11}$ rather than a standard bodyweight-based starting dose.

\section{Patient population}

Patients were eligible for participation in this study if they were at least 18 years old and were scheduled to undergo a HLA and blood group $\mathrm{ABO}$ compatible kidney transplantation with a living donor in the Erasmus MC, University Medical Center Rotterdam, The Netherlands. Patients had to receive tacrolimus as part of their initial immunosuppressive therapy. Exclusion criteria were (1) tacrolimus treatment in the 28 days before the kidney transplantation, (2) the use of drugs having a pharmacokinetic interaction with tacrolimus (Table S1) in the 28 days prior to the kidney transplantation, or (3) a multi-organ transplantation.

\section{Intervention and additional immunosuppressive treatment}

All patients included in this trial received a tacrolimus starting dose (Prograft; Astellas Pharma, Leiden, The Netherlands) based on an internally and externally validated dosing algorithm, as described by Andrews et al., ${ }^{11}$ rather than the standard, bodyweight-based starting dose $(0.2 \mathrm{mg} / \mathrm{kg} /$ day $)$. The algorithm included age, BSA, and CYP $3 A 4$ and $C Y P 3 A 5$ genotypes. Carriers of at least one $C Y P 3 A 5^{*} 1$ allele were considered CYP3A5 expressers. ${ }^{11}$

$$
\begin{gathered}
\text { Dose }(\mathrm{mg})=222 \mathrm{ng} . \mathrm{h} / \mathrm{mL} * 22.5 \mathrm{~L} / \mathrm{hr} \\
*[(1.0, \text { if } C Y P 3 A 5 * 3 / * 3) \text { or }(1.62, \text { if } C Y P 3 A 5 * 1 / * 3 \text { or } C Y P 3 A 5 * 1 / * 1)] \\
*[(1.0, \text { if } C Y P 3 A 4 * 1 \text { or unknown }) \text { or }(0.814, \text { if } C Y P 3 A 4 * 22)] *\left(\frac{\text { Age }}{56}\right)^{-0.50} \\
*\left(\frac{\mathrm{BSA}}{1.93}\right)^{0.72} / 1000
\end{gathered}
$$

The calculated total daily dose was divided in two equal doses which were rounded off to the nearest $0.5 \mathrm{mg}$ and administered to each patient every 12 hours (at 10:00 and 22:00 hours, starting on the night after transplant surgery). Patients received 5 unaltered doses of the calculated tacrolimus dose until the morning of postoperative day 3 , which was considered the first steady-state concentration. Thereafter, TDM was performed as part of routine clinical care aiming for wholeblood tacrolimus $\mathrm{C}_{0}$ of 7.5 to $12.5 \mathrm{ng} / \mathrm{mL}$ in weeks 1 to 2 .

All patients received induction therapy with basiliximab (Simulect; Novartis Pharma B.V., Arnhem, The Netherlands; $20 \mathrm{mg}$ on days 0 and 4 after transplantation), mycophenolate mofetil (Cellcept; Roche Pharmaceuticals, Woerden, The Netherlands; started in a dose of $1,000 \mathrm{mg}$ orally twice daily, aiming for a plasma $\mathrm{C}_{0}$ of $1.5-3.0 \mathrm{mg} / \mathrm{L}$ ) and glucocorticoids. Patients received i.v. prednisolone in a dose of $50 \mathrm{mg}$ twice daily on days $0-3$. Thereafter, patients were administered an oral dose of $20 \mathrm{mg}$ prednisolone once daily (days 4-14 posttransplantation), after which the dose was lowered to $15 \mathrm{mg}$ once daily (days 15-28) and then tapered to $5 \mathrm{mg}$ at month 3 post-transplantation.

\section{CYP3A genotyping}

During their work-up for living donor kidney transplantation, patients were genotyped for CYP3A4 and CYP3A5. DNA was extracted from buccal mucosa, which was collected with a buccal swap. Samples were analyzed for the presence of the CYP $3 A 4^{*} 1 /^{*} 22$ and $C Y P 3 A 5^{*} 1 /^{*} 3$ single-nucleotide polymorphisms using Autogenomics INFINITY micro-arrays (Autogenomics, Carlsbad, CA), according to the manufacturer's instructions. Genotyping was performed in accordance with standard laboratory procedures in an ISO15189 certified laboratory. For the calculation of the starting dose, ${ }^{11} \mathrm{pa}-$ tients carrying at least one $C Y P 3 A 5^{*} 1$ allele were considered a CYP3A5 expresser. 


\section{Tacrolimus sampling and measurement}

Blood samples were collected for tacrolimus $\mathrm{C}_{0}$ measurement on postoperative days 3, 5, 7, and 10 during hospitalization and whenever deemed necessary by the attending physician (but not before day 3). Moreover, the tacrolimus $\mathrm{C}_{0}$ was measured on the morning of a for-cause transplant biopsy. A validated liquid chromatography-tandem mass spectrometry method was used to determine tacrolimus concentrations in whole-blood samples in an ISO15189 certified laboratory. The imprecision of this method is $<10 \%$ with a bias $<15 \%$ over the validated range $1.0-35.0 \mathrm{ng} / \mathrm{mL}$.

\section{Study end points}

The aim of this study was to increase the percentage of patients with a tacrolimus $\mathrm{C}_{0}$ within the therapeutic range and to minimize the occurrence of tacrolimus underexposure and overexposure in the early phase after renal transplantation by using a dosing algorithm to guide the tacrolimus starting dose. The primary end point of this study was the proportion of patients within the target tacrolimus $\mathrm{C}_{0}$ range (7.5-12.5 ng/ $\mathrm{mL}$ ) on the morning of the third day after renal transplantation. The outcomes were interpreted with respect to a historical control group, in which renal allograft recipients received a tacrolimus starting dose based on bodyweight $(0.2 \mathrm{mg} / \mathrm{kg}$ per day). ${ }^{7}$ Moreover, the tacrolimus $\mathrm{C}_{0}$ that patients would have had if they would have received a standard bodyweight-based tacrolimus dose was estimated (see below) to evaluate model performance.

Secondary study end points were (1) the proportion of patients with a markedly supratherapeutic $(>20 \mathrm{ng} / \mathrm{mL})$ or subtherapeutic $(<5 \mathrm{ng} / \mathrm{mL})$ tacrolimus $\mathrm{C}_{0}$ on the third day posttransplantation, (2) the proportion of patients within the tacrolimus target $\mathrm{C}_{0}$ range on postoperative days 5,7 , and 10 , and (3) the time to reach the target tacrolimus $\mathrm{C}_{0}$. Secondary clinical end points included the incidence of biopsy-proven acute rejection (BPAR), post-transplant diabetes mellitus (PTDM), and the number of serious adverse events (SAEs) within the first 30 days post-transplantation. Biopsies were performed for-cause only and were assessed and graded according to the Banff 2019 update by a renal pathologist. ${ }^{31}$ PTDM was defined as the use of glucose-lowering medical therapy on day 30 post-transplantation in a patient not needing such treatment before transplantation. The following data on renal function was collected: serum creatinine concentration, Chronic Kidney Disease Epidemiology Collaboration estimated glomerular filtration rate, and the protein/creatinine ratio in urine. ${ }^{32}$ The total follow-up period was 30 days after renal transplantation.

\section{Sample size calculation and statistical analysis}

A Simon 2-stage design was used for sample size calculation. ${ }^{33}$ In a historical cohort, consisting of 99 patients transplanted in the Erasmus MC, $37.4 \%$ of the patients treated with the standard, bodyweight-based tacrolimus starting dose had a tacrolimus $\mathrm{C}_{0}$ within the target range $(10-15 \mathrm{ng} / \mathrm{mL})$ on the third day post-transplantation. With algorithm-based dosing, a proportion of $55 \%$ of the patients was expected to be within the target tacrolimus $\mathrm{C}_{0}$ range on the third day post-transplantation. Therefore, $\mathrm{P}_{0}=37.4 \%$ and $\mathrm{P}_{1}=55.0 \%$ were used as design parameters. Together with $\alpha=0.10$ and $\beta=0.10$, the required number of patients in this study was 56 , with one preplanned interim analysis after the first 27 included patients. If, after the inclusion of 56 patients, at least 26 patients had a tacrolimus $\mathrm{C}_{0}$ within the target range on the third day post-transplantation, the conclusion of this trial would be that algorithm-based dosing is effective and results in a sufficiently high proportion of patients with an adequate tacrolimus $\mathrm{C}_{0}$ to warrant further research in this population. To account for a dropout rate of $7 \%$, a total of 60 patients was included in this clinical trial. If at the interim analysis, only $\leq 10$ of the first 27 patients would have had a tacrolimus $\mathrm{C}_{0}$ within the therapeutic target range on day 3 after transplantation, inclusion of further patients would have been terminated, otherwise inclusion would be extended to a total of 60 patients.

All statistical analyses were performed in R (version 3.5.3) ) $^{34}$ following an intention-to-treat approach. Only in case of a protocol violation (i.e., if the tacrolimus concentration was measured before the third post-operative day resulting in a dose adjustment), the patient was excluded from the analysis. The primary end point is presented as number of cases with a tacrolimus $\mathrm{C}_{0}$ within the target range with a proportion and a $90 \%$ confidence interval (CI). Descriptive statistics were used to evaluate secondary end points of the study population. Categorical variables were described as number of cases with a percentage. Continuous variables were described as median with interquartile range (IQR). A Kaplan-Meier survival analysis was used to evaluate the time to target concentration.

\section{Estimated tacrolimus $\mathbf{C}_{0}$}

In order to evaluate the performance of the model, we estimated the tacrolimus $\mathrm{C}_{0}$ that patients would have had if they would have received a standard bodyweight-based tacrolimus starting dose. The estimated tacrolimus $\mathrm{C}_{0}$ was calculated using the following information: the algorithm-based dose (administered), the observed tacrolimus $\mathrm{C}_{0}$ on day 3 (measured), and the bodyweightbased dose (not administered):

Estimated tacrolimus $\mathrm{C} 0=\frac{\text { bodyweight based dose } * \text { observed tacrolimus } \mathrm{C} 0}{\text { algorithm based dose }}$

\section{Ethical considerations}

This clinical trial was performed in accordance with the principles of the Declaration of Helsinki (seventh revision, October 2013, approved by the 64th WMA General Assembly, Fortaleza, Brazil) and the Medical Research Involving Human Subjects Act (WMO). Study procedures were performed in accordance with the ethical standards of the institutional research committee (Erasmus MC Medical Ethical Review Board, number 2018-157). The trial was registered (19-10-2018) in the Dutch national trial registry (https://www.trialregister.nl/ trial/7360). Written informed consent was obtained from all patients prior to inclusion. 


\section{RESULTS}

In the period of February 23, 2019 (first patient, first visit) until July 7, 2020 (last patient, first visit), 227 patients received a kidney transplant at the Erasmus MC. Ninety-seven (42.7\%) of these patients were eligible for participation in this study, of whom 60 patients were included (Figure 1). After inclusion, in one patient, the tacrolimus concentration was inadvertently measured before the third post-operative day (before steady-state), followed by a dose adjustment. This patient was considered to have a protocol violation and was excluded from the analysis, resulting in a total of 59 patients for the intention-to-treat analysis.

\section{Baseline characteristics}

Table 1 presents the baseline characteristics of the included patients. The median age at the time of transplantation was 59 years (IQR 4867). White ethnicity was the most prevalent (90\%). CYP3A4 and CYP3A5 genotype frequencies (Table 1) were in accordance with the Hardy-Weinberg equilibrium $\left(\chi^{2}=0.40 ; P=0.53\right.$ and $\chi^{2}=1.03$; $P=0.31$, respectively). Nine participants $(15 \%)$ carried a $C Y P 3 A 4^{*} 22$ allele and 14 participants (24\%) were CYP3A5 expressers (carriers of at least one ${ }^{*} 1$ allele). None of the patients started comedication known to interact with tacrolimus during the study period.

\section{Primary end point: Achievement of the target range}

Thirty-four of the 59 patients (58\%; 90\% CI 47\%-68\%) had a tacrolimus $\mathrm{C}_{0}$ within the target concentration range $(7.5-12.5 \mathrm{ng} / \mathrm{mL})$ on day 3 after transplantation (Table 2; Figure 2). The median tacrolimus $\mathrm{C}_{0}$ on day 3 was $8.4 \mathrm{ng} / \mathrm{mL}$ (IQR 6.9-10.4). The median algorithm-based starting dose was $10.0 \mathrm{mg} /$ day (IQR 9.0-14.5).

\section{Secondary pharmacokinetic end points}

Seventeen patients (29\%; 90\% CI 19\%-39\%) had a tacrolimus $\mathrm{C}_{0}$ below $7.5 \mathrm{ng} / \mathrm{mL}$, whereas 8 patients (14\%; 90\% CI 6\%-21\%) had a tacrolimus $\mathrm{C}_{0}$ above $12.5 \mathrm{ng} / \mathrm{mL}$ (Table 2; Figure 2). Four of 59 patients (7\%; $90 \%$ CI 1\%-12\%) had a markedly low tacrolimus $\mathrm{C}_{0}$ $(<5.0 \mathrm{ng} / \mathrm{mL})$ and 2 patients $(3 \%$; $90 \% \mathrm{CI} 0 \%-7 \%)$ had a markedly high tacrolimus $\mathrm{C}_{0}(>20.0 \mathrm{ng} / \mathrm{mL}$; Table 2$)$.

The median time to reach the target tacrolimus $\mathrm{C}_{0}$ for the first time, was 3 days (Figure 3). On day 5 post-transplantation, 35 of 57 patients $(61 \%$; $90 \%$ CI $51 \%-72 \%)$ had a tacrolimus $\mathrm{C}_{0}$ concentration within the target range. This increased to 29 of 44 patients (66\%; $90 \%$ CI $54 \%-78 \%)$ on day 7 and to 25 of 37 patients $(68 \%$; 90\% CI 55\%-80\%) on day 10 after transplantation (Figure 2). The other patients had been discharged from the hospital before postoperative day 10 and, therefore, no blood samples of these

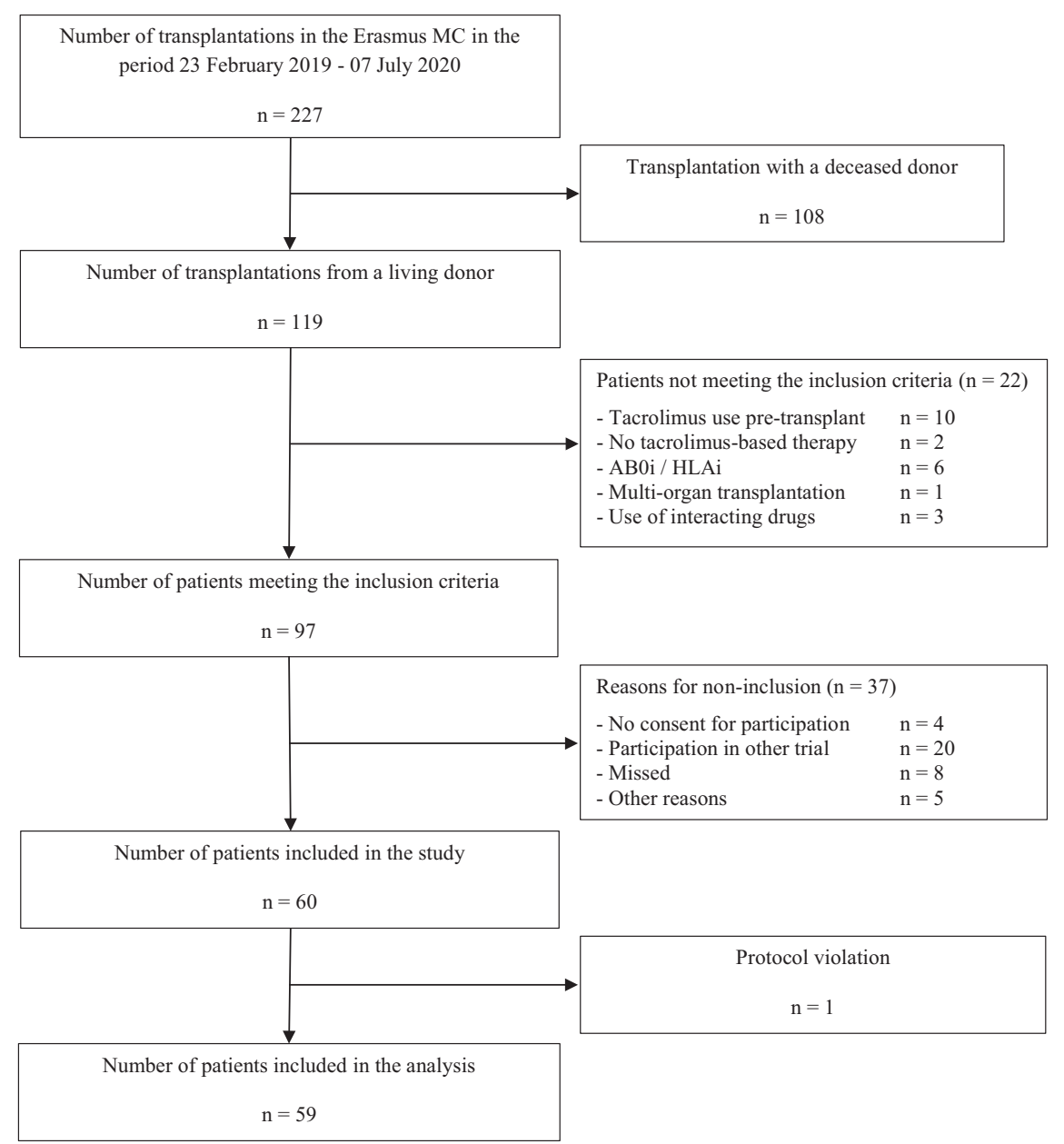

Figure 1 Flowchart of the trial depicting the inclusion and exclusion of patients. ABOi, blood group incompatibility; HLAi, human leukocyte antigen incompatibility. 
Table 1 Baseline characteristics

\begin{tabular}{|c|c|}
\hline Recipient characteristics & Study population $(n=59)$ \\
\hline \multicolumn{2}{|l|}{ Gender } \\
\hline Female/Male & $22(37 \%) / 37(63 \%)$ \\
\hline Age (years) & $\begin{array}{l}59 \text { (IQR 48-67; } \\
\text { range 19-83) }\end{array}$ \\
\hline Bodyweight (kg) & $\begin{array}{l}80.0 \text { (IQR 71.2-90.0; } \\
\text { range 49.3-119.5) }\end{array}$ \\
\hline Length (cm) & $\begin{array}{l}176.0 \text { (IQR 170.0-180.5; } \\
\text { range 156.0-202.0) }\end{array}$ \\
\hline $\mathrm{BMI}\left(\mathrm{kg} / \mathrm{m}^{2}\right)$ & $\begin{array}{l}26.2 \text { (IQR 23.5-28.9; } \\
\text { range } 17.7-37.2 \text { ) }\end{array}$ \\
\hline $\mathrm{BSA}\left(\mathrm{m}^{2}\right)$ & $\begin{array}{l}1.99 \text { (IQR 1.85-2.08; } \\
\text { range 1.47-2.53) }\end{array}$ \\
\hline \multicolumn{2}{|l|}{ Ethnicity } \\
\hline African & $3(5 \%)$ \\
\hline Asian & $1(2 \%)$ \\
\hline Caucasian & $53(90 \%)$ \\
\hline Other & $2(3 \%)$ \\
\hline \multicolumn{2}{|l|}{ CYP3A4 genotype } \\
\hline *22 carrier/*22 non-carrier & $9(15 \%) / 50(85 \%)$ \\
\hline \multicolumn{2}{|l|}{ CYP3A5 genotype } \\
\hline Expresser/non-expresser & $14(24 \%) / 45$ (76\%) \\
\hline \multicolumn{2}{|c|}{ RRT prior to kidney transplantation } \\
\hline Hemodialysis & $14(24 \%)$ \\
\hline Peritoneal dialysis & $9(15 \%)$ \\
\hline Pre-emptive & $36(61 \%)$ \\
\hline
\end{tabular}

Number of kidney transplantations

$1^{\text {st }} / 2^{\text {nd }} / 3^{\text {rd }} \quad 58(98 \%) / 0(0 \%) / 1(2 \%)$

Donor type

\begin{tabular}{lc}
\hline \multicolumn{1}{c}{ Living related/Living unrelated } & $20(34 \%) / 39(66 \%)$ \\
\hline PRA current & \\
\hline$<15 \% />15 \%$ & $55(93 \%) / 4(7 \%)$ \\
\hline PRA peak & $56(95 \%) / 3(5 \%)$ \\
\hline$<15 \% />15 \%$ &
\end{tabular}

Continuous variables are described as median (IQR; range). Categorical variables as number of cases (\%).

BMI, body mass index; PRA, panel reactive antibodies; RRT, renal replacement therapy.

patients were available. The median number of dose adjustments to reach the tacrolimus target range was 0 (range $0-2$ ). The median number of dose-adjustments up until day 10 after transplantation was 1 (range $0-3$ ).

\section{Estimated tacrolimus $\mathbf{C}_{0}$ after bodyweight-based dosing}

The median calculated bodyweight-based dose $(0.2 \mathrm{mg} / \mathrm{kg}$; not administered) was $16.0 \mathrm{mg} /$ day (IQR 14.0-18.0). The difference between the algorithm-based (administered) and the bodyweightbased (hypothetical) starting dose of the participants in this trial ranged between $-14.0 \mathrm{mg}$ and $+6.0 \mathrm{mg}$, with a median of $-5.0 \mathrm{mg}$ (Table 2). This indicates that in most patients, the algorithm recommended a lower dose than standard. This was most
Table 2 Pharmacokinetic outcomes

\begin{tabular}{|c|c|}
\hline Outcome & $(n=59)$ \\
\hline \multicolumn{2}{|l|}{ Tacrolimus doses } \\
\hline Algorithm-based dose, mg/day & $\begin{array}{l}10.0 \text { (IQR 9.0-14.5; } \\
\text { range 6.0-22.0) }\end{array}$ \\
\hline $\begin{array}{l}\text { Bodyweight-based dose, } \\
\text { mg/day }\end{array}$ & $\begin{array}{l}16.0 \text { (IQR 14.0-18.0; } \\
\text { range 10.0-24.0) }\end{array}$ \\
\hline Dose difference, mg/day & $\begin{array}{l}-5.0(\mathrm{IQR}-7.0 \text { to }-2.0 ; \\
\text { range }-14.0-6.0)\end{array}$ \\
\hline \multicolumn{2}{|l|}{ Primary end point } \\
\hline On target day $3, n$ & 34 (58\%; 90\% Cl 47\%-68\%) \\
\hline $\begin{array}{l}\text { Tacrolimus concentration day } \\
3, \mathrm{ng} / \mathrm{mL}\end{array}$ & $\begin{array}{l}8.4 \text { (IQR 6.9-10.4; } \\
\text { range 3.9-33.0) }\end{array}$ \\
\hline$<7.5 \mathrm{ng} / \mathrm{mL}$ day $3, n$ & 17 (29\%; 90\% Cl 19\%-39\%) \\
\hline$>12.5 \mathrm{ng} / \mathrm{mL}$ day $3, n$ & 8 (14\%; 90\% Cl 6\%-21\%) \\
\hline \multicolumn{2}{|l|}{ Secondary end points } \\
\hline$<5.0 \mathrm{ng} / \mathrm{mL}$ day $3, n$ & 4 (7\%; 90\% Cl 1\%-12\%) \\
\hline$>20.0 \mathrm{ng} / \mathrm{mL}$ day $3, n$ & 2 (3\%; 90\% Cl 0\%-7\%) \\
\hline On target day $5, n$ & $35 / 57$ (61\%; 90\% Cl 51\%-72\%) \\
\hline On target day $7, n$ & 29/44 (66\%; 90\% Cl 54\%-78\%) \\
\hline On target day $10, n$ & 25/37 (68\%; $90 \%$ Cl 55\%-80\%) \\
\hline $\begin{array}{l}\text { Tac concentration day } 5 \text {, } \\
\mathrm{ng} / \mathrm{mL}\end{array}$ & $\begin{array}{l}9.0 \text { (IQR 7.8-11.9; } \\
\text { range 5.8-22.2) }\end{array}$ \\
\hline $\begin{array}{l}\text { Tac concentration day } 7 \text {, } \\
\mathrm{ng} / \mathrm{mL}\end{array}$ & $\begin{array}{l}\text { 10.4 (IQR 9.2-12.3; } \\
\text { range 5.3-25.7) }\end{array}$ \\
\hline $\begin{array}{l}\text { Tac concentration day } 10 \text {, } \\
\mathrm{ng} / \mathrm{mL}\end{array}$ & $\begin{array}{l}10.4 \text { (IQR 9.0-12.7; } \\
\text { range 5.3-21.3) }\end{array}$ \\
\hline
\end{tabular}

Continuous variables are described as median (IQR; range). Categorical variables as number of cases, $n$ (\%, $90 \%$ confidence interval).

$\mathrm{Cl}$, confidence interval; IQR, interquartile range.

pronounced in obese patients and in CYP3A5 nonexpressers (Table S2; Figures S1, S2).

The median estimated tacrolimus concentration on day 3 after transplantation was $11.4 \mathrm{ng} / \mathrm{mL}$ (IQR 8.5-17.8; range 4.2-49.5). Of 59 patients, 23 (39\%) were estimated to have been within the target tacrolimus concentration range if their starting dose would have been based on bodyweight alone rather than on the algorithm (Figure S3). Nine patients (15\%) were estimated to have had a subtherapeutic tacrolimus $\mathrm{C}_{0}$ on day 3 , whereas 27 patients (46\%) would have been expected to have reached a supratherapeutic tacrolimus $\mathrm{C}_{0}$ at this same time point. One patient $(2 \%)$ was estimated to have reached a tacrolimus $\mathrm{C}_{0}<5.0 \mathrm{ng} / \mathrm{mL}$, and $10 \mathrm{pa}-$ tients $(17 \%)$ were estimated to have had a tacrolimus $\mathrm{C}_{0}>20 \mathrm{ng} /$ $\mathrm{mL}$. These data demonstrate that the algorithm mainly reduced the incidence of tacrolimus overexposure.

\section{Clinical outcomes}

All 59 patients that were included in this analysis, survived the first post-transplant month, and completed the 30 -day follow-up. At the end of follow-up, all patients had a functioning graft. At day 30 , the median serum creatinine concentration was $134 \mu \mathrm{mol} / \mathrm{L}$ (IQR 110-162), the median estimated glomerular filtration rate was $46 \mathrm{~mL} / \mathrm{min}$ per $1.73 \mathrm{~m}^{2}$ (IQR 39-52), and the median urinary 
(a) Tacrolimus concentrations on days $3,5,7$, and 10

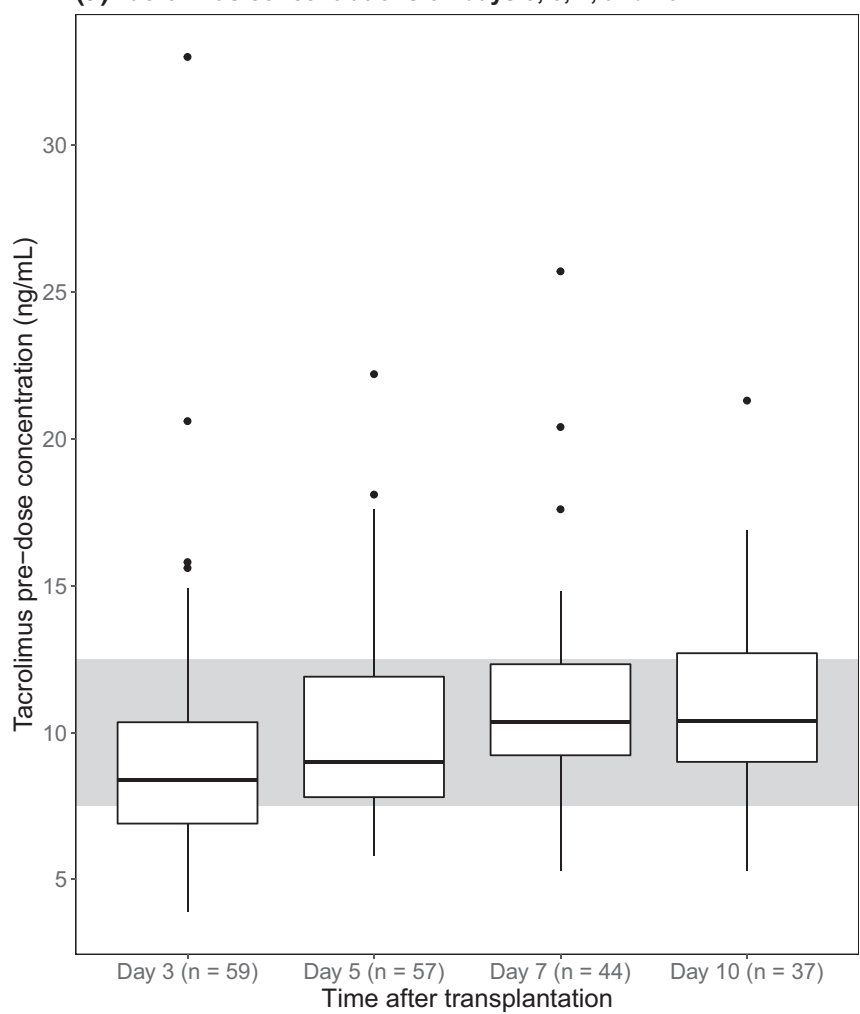

(b) Individual tacrolimus concentrations on days 3, 5, 7, and 10

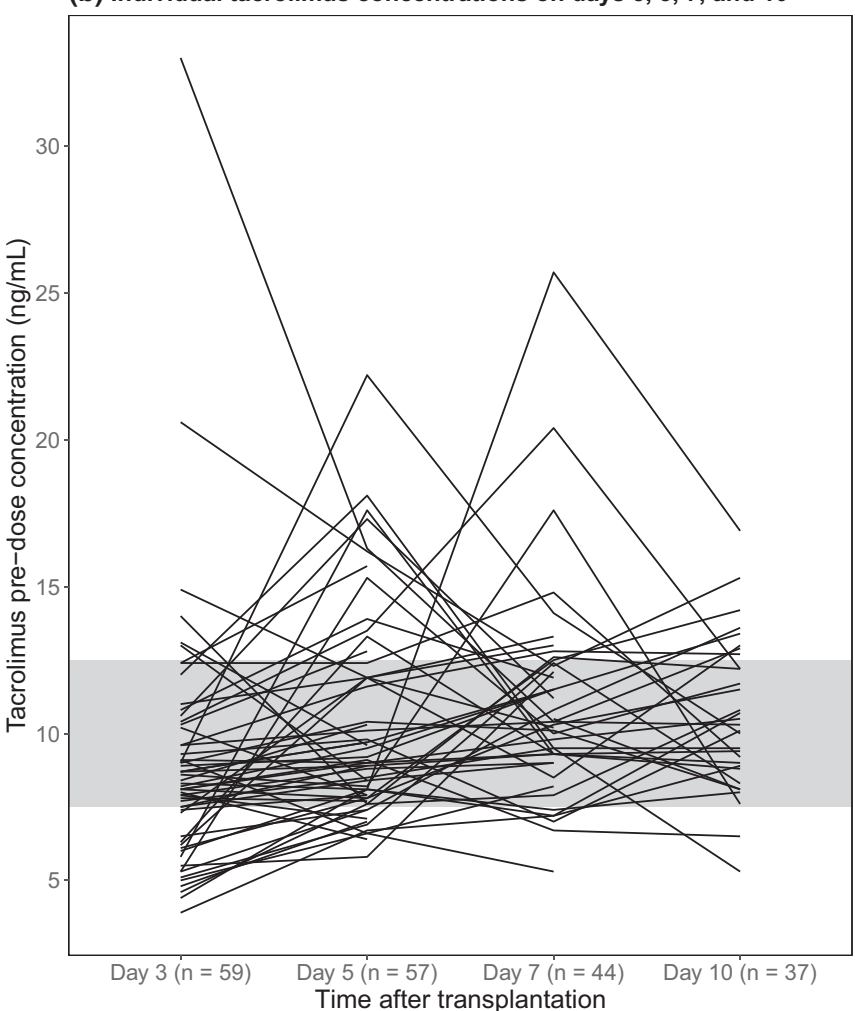

Figure 2 (a) Boxplot of the tacrolimus $\mathrm{C}_{0}$ on days 3, 5, 7, and 10 after transplantation. The box corresponds with the 25th percentile (lower boundary), the median (middle line), and the 75th percentile (upper boundary). The upper whisker reaches to the highest value up until 1.5 times the interquartile range (IQR). The lower whisker reaches the lowest value up until 1.5 times the IQR. Values outside these ranges are considered outliers and are represented as dots. The grey area represents the target tacrolimus $\mathrm{C}_{0}$ range $(7.5-12.5 \mathrm{ng} / \mathrm{mL})$. (b) Spaghetti plot of the individual tacrolimus $\mathrm{C}_{0}$ on days $3,5,7$, and 10 after transplantation. The grey area represents the target tacrolimus $\mathrm{C}_{0}$ range $(7.5-$ $12.5 \mathrm{ng} / \mathrm{mL})$.

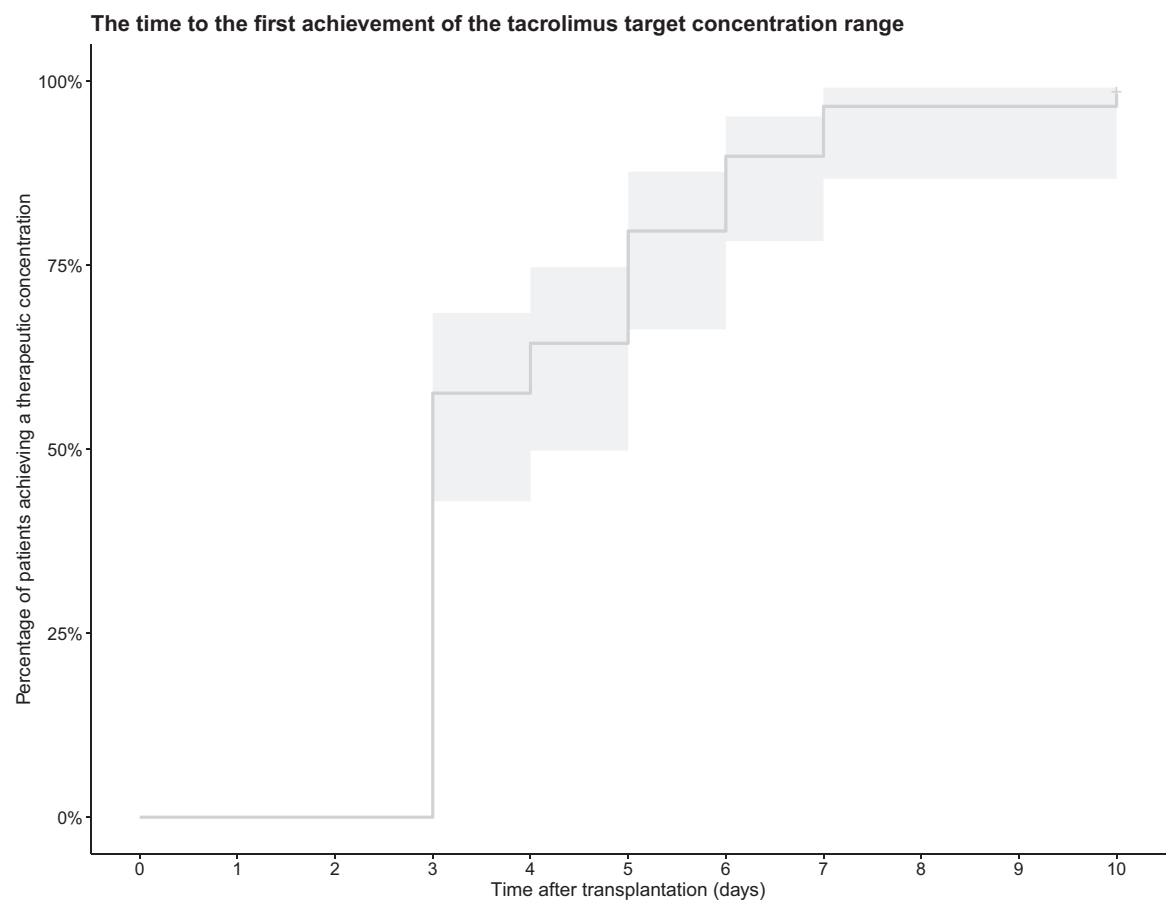

Figure 3 Kaplan-Meier curve depicting the time to the first achievement of a tacrolimus concentration within the target range (7.5-12.5 ng/ $\mathrm{mL}$ ), with its $95 \%$ confidence interval (shaded area). The median time to target was 3 days. 
Table 3 Banff 19 classification of rejections occurring within the $\mathbf{3 0}$ days after transplantation

\begin{tabular}{lc}
\hline Rejection type & $(n=59)$ \\
\hline bTCMR & $1(2 \%)$ \\
\hline aTCMR type & 0 \\
\hline $1 \mathrm{~A}$ & 0 \\
\hline $1 \mathrm{~B}$ & $2(3 \%)$ \\
\hline $2 \mathrm{~A}$ & $1^{\mathrm{a}}(2 \%)$ \\
\hline $2 \mathrm{~B}$ & 0 \\
\hline aABMR & $3^{\mathrm{a}}(5 \%)$ \\
\hline Total BPAR
\end{tabular}

aABMR, active, antibody-mediated rejection; aTCMR, acute T cell-mediated rejection; BPAR, biopsy-proven acute rejection; bTCMR, borderline (suspicious for) T cell-mediated rejection.

Depicted are the number of patients (\%).

${ }^{a}$ One patient had two reported rejection episodes (both classified as aTCMR 2B).

protein/creatinine ratio was $21.8 \mathrm{~g} / \mathrm{mol}$ creatinine (IQR 12.1 30.3). The median length of hospital stay was 10 days (IQR 7-10).

BPAR complicated transplantation in 3 patients within 30 days after transplantation (5\%; Table 3 ). In one of these three patients, acute T-cell-mediated rejection was also diagnosed in a follow-up biopsy (and treated with alemtuzumab). In one patient, borderline (suspicious) for acute T-cell mediated rejection was diagnosed (and treated with methylprednisolone).

Eight other patients received antirejection therapy. Three of these patients had histomorphological signs suspicious for active antibody-mediated rejection (aABMR) in their biopsy, but did not meet the full Banff 2019 criteria for this diagnosis. Of these three, one patient had microvascular inflammation suspicious for aABMR, but immunohistochemistry was negative for $\mathrm{C} 4 \mathrm{~d}$ and no donor-specific anti-HLA antibodies were detected. Two of these three patients had thrombotic microangiopathy, but a negative C4d staining and again, no evidence of donor-specific anti-HLA antibodies. All three patients were treated with methylprednisolone and i.v. immunoglobulins. Three other cases were treated for rejection pending the results of the biopsy but only had acute tubular necrosis in their biopsy. The two remaining patients had presumed clinical rejection and antirejection treatment was started but no biopsy was performed (because of the use of anticoagulant therapy in one case and improvement of kidney function after antirejection treatment in the other case).

On the day of the biopsy (on days 3,7, and 8 post-transplantation, respectively) the three patients with BPAR had a tacrolimus $\mathrm{C}_{0}$ of $4.4,10.4$, and $11.7 \mathrm{ng} / \mathrm{mL}$, respectively (Figure $\mathbf{S 4}$ ). On day 3 after transplantation, 2 of the patients with BPAR were on target; the third patient with BPAR had a tacrolimus $\mathrm{C}_{0}$ of $4.4 \mathrm{ng} /$ $\mathrm{mL}$ at first steady-state. This patient was a 65 -year-old man with a bodyweight of $85.5 \mathrm{~kg}$, a BSA of $2.05 \mathrm{~m}^{2}$, and a $C Y P 3 A 4^{*} 1{ }^{*} 1$ and CYP $3 A 5^{*} 3 /^{*} 3$ genotype. Additional post hoc genotyping demonstrated that he had the $P O R^{*} 1 /^{*} 28$ genotype. He did not use any interacting comedication and did not receive erythrocyte transfusions. He was discharged on day 11 with a tacrolimus dose of $5 \mathrm{mg}$ twice-daily, which corresponded exactly to the starting dose predicted by the algorithm.
Table 4 SAEs occurring within the 30 days after transplantation

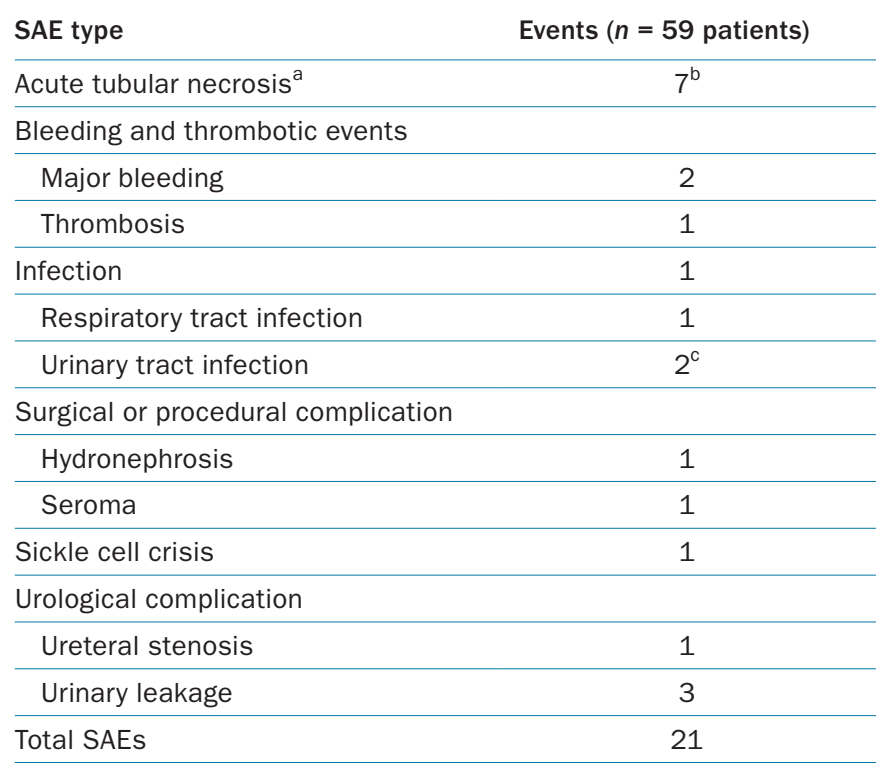

SAEs, serious adverse events.

${ }^{\mathrm{a}}$ All diagnosed by kidney transplant biopsy.

${ }^{\mathrm{b}}$ One of these patients experienced delayed graft function.

'Urosepsis in the same patient.

A total of 21 SAEs (other than BPAR, borderline rejection, suspected aABMR, acute tubular necrosis treated as rejection, and presumed rejection) were reported in 59 participants (Table 4). PTDM occurred in six patients (10\%).

\section{DISCUSSION}

In this prospective intervention trial, a tacrolimus dosing algorithm, which included the covariates age, BSA, and CYP3A4 and CYP $3 A 5$ genotypes, ${ }^{11}$ successfully predicted the tacrolimus starting dose of renal transplant recipients. With algorithmguided tacrolimus dosing, $58 \%$ of the patients had a tacrolimus $\mathrm{C}_{0}$ within the target concentration range at first steady-state (day 3 after transplantation). In a historical cohort in which the starting dose was based on bodyweight alone, this was $37.4 \%{ }^{7}$ In other studies, even lower proportions of patients reaching the target concentration after initial bodyweight-based dosing were observed: $18.5 \%$ and $29.1 \% .{ }^{8,9}$ Following the decision rules of the Simon 2-stage design, we can conclude that algorithm-based tacrolimus dosing is effective and results in a sufficiently high proportion of patients on target to warrant further research in this study population.

The use of algorithm-based dosing seemed to especially reduce overexposure in the early phase after renal transplantation. A markedly high tacrolimus concentration was observed in only $3 \%$ of the renal transplant recipients, whereas this was $19 \%$ in the historical cohort, in which bodyweight-based dosing was applied. This likely relates to the relatively high proportion of CYP3AS nonexpressers in our mainly White population. These slow metabolizers are likely to be overdosed when standard, bodyweight-based doses are prescribed. The risk of overexposure following bodyweight-based 
dosing seems to be especially high in obese patients (body mass index $>30 \mathrm{~kg} / \mathrm{m}^{2}$ ), who made up $20.3 \%$ of the population of this study.

A markedly low tacrolimus concentration was observed in $7 \%$ of the patients on day 3 post-transplantation, whereas this was $3 \%$ in the historical cohort. Although underexposure seems to occur more often than overexposure when using the dosing algorithm, the proportion of patients with BPAR in the present study was low (5\%) as was expected for a low immunological risk population, and appears to be similar to the proportion of patients with BPAR after bodyweight-based dosing $(6.7 \%$ within the first month and $10.1 \%$ within 3 months after renal transplantation). ${ }^{7}$ We could not identify factors that caused the low tacrolimus $\mathrm{C}_{0}$ in the one patient that experienced BPAR and early underexposure. Although this patient had the $P O R^{*} 1 /{ }^{*} 28$ genotype (associated with a higher tacrolimus dose requirement), an effect of this polymorphism has only been observed in CYP3A5 expressers. ${ }^{35-37}$ The present incidence of PTDM of $10 \%$ is in line with literature. ${ }^{38,39}$ Although a number of SAEs occurred, this is not unexpected in a renal transplant population and the SAEs seemed not to be related to the use of the dosing algorithm. Because tacrolimus underexposure and overexposure have been associated with an increased risk of rejection and drug-related toxicity, respectively, ${ }^{12,40,41}$ it is important to minimize the time a patient's tacrolimus exposure is outside the target range. In this trial, the median time to achieve the target concentration was 3 days. In the historical cohort, a median time to reach the target concentration of 6 days was observed, whereas this was 7 days in another study. ${ }^{7,9}$

The slow increase in the proportion of patients with tacrolimus concentrations within the target range after the third postoperative day can be partly explained by intrapatient variability, as some patients with a tacrolimus $\mathrm{C}_{0}$ within the target range on a certain day had a tacrolimus $\mathrm{C}_{0}$ outside the target range on a subsequent day. This may be explained by changes in, among others, the concentration of tacrolimus-binding proteins (including albumin) and hematocrit. Computerized dosing after transplantation may further improve tacrolimus treatment. In a randomized, controlled trial by Størset et al. ${ }^{42}$ kidney transplant recipients in the experimental arm were treated with computerbased tacrolimus dosing. In the control arm, tacrolimus doses were adjusted by experienced clinical staff. All patients received a bodyweight-based tacrolimus starting dose and then a tacrolimus $\mathrm{C}_{0}$ was determined on day 1 or 2 post-transplantation. Subsequent tacrolimus doses were then based on this $\mathrm{C}_{0}$ by either the computer or the clinician. The trial of Størset et al. ${ }^{42}$ demonstrated that computerized dosing leads to a higher proportion of patients within the tacrolimus target $\mathrm{C}_{0}$ range compared with physician-based dosing. Together with the results of the present trial, we think that, in the future, a further refinement of tacrolimus therapy may be achieved by using computerized dosing for both the calculation of the tacrolimus starting dose, and for subsequent dose adjustments.

A limitation of this study is its single-arm design. Therefore, it does not provide the ultimate proof that algorithm-based tacrolimus start-dosing outperforms standard, bodyweight-based dosing. This question can only be answered by a randomized, controlled clinical trial. Because several previously developed algorithms did not perform well when tested prospectively, ${ }^{18,30}$ we decided to first investigate the clinical efficacy of our algorithm in this single arm pilot study before embarking on a large randomized, controlled clinical trial. Another limitation of this trial is the fact that different target tacrolimus concentration ranges were aimed for in the present and historical cohort. This reflects the changed clinical practice. ${ }^{43,44}$ In the historical cohort, which was used for the power calculation, the tacrolimus target concentration ranged from 10.0 to $15.0 \mathrm{ng} / \mathrm{mL}$, whereas the target concentration in the present trial ranged from 7.5 to $12.5 \mathrm{ng} / \mathrm{mL}$ (which is also the current target range for routine clinical practice in our center). When looking back at the data of the historical cohort, $36.4 \%$ of the patients with a standard, bodyweight-based dose, had a tacrolimus concentration within the $7.5-12.5 \mathrm{ng} / \mathrm{mL}$ concentration range on day 3 posttransplantation. Because this proportion is even lower than the $37.4 \%$ we used to design the present study, we feel that adaptation of the target tacrolimus concentration range of the historical cohort for the determination of the decision parameters, would not have altered the conclusions of this trial. Third, a significant number of patients had a tacrolimus concentration outside the target concentration range despite the use of the algorithm. The causes of this unexplained variability are unclear, but may relate to other genetic variation in tacrolimus-metabolizing enzymes $^{35,37,45}$ or to interindividual differences in the intestinal microbiome. ${ }^{46-48}$ Finally, the present algorithm was not tested in recipients of a deceased donor kidney transplant. We are currently improving our algorithm so that it can be used for all types of kidney transplantation.

In conclusion, basing the tacrolimus starting dose on a dosing algorithm is effective in the prediction of an individual's tacrolimus dose requirement as it leads to the achievement of the tacrolimus target $\mathrm{C}_{0}$ in as much as $58 \%$ of the patients on day 3 after kidney transplantation. Although a randomized clinical trial is required to demonstrate the superiority of algorithm-based dosing over conventional bodyweight-based dosing, the use of a dosing-algorithm appears to reduce off-target exposure to tacrolimus in the critical early phase after transplantation and therefore has the potential to improve clinical outcomes.

\section{SUPPORTING INFORMATION}

Supplementary information accompanies this paper on the Clinical Pharmacology \& Therapeutics website (www.cpt-journal.com).

\section{ACKNOWLEDGMENTS}

The authors would like to thank Mrs. Oudhuizen-van Reen and Mrs. van Oers for the clinical assistance in the collection of the blood samples.

\section{FUNDING}

No funding was received for this work.

\section{CONFLICTS OF INTEREST}

D.A.H. has received grant support (paid to his institution) from Astellas Pharma, Chiesi Farmaceutici SpA, and Bristol Myers-Squibb, as well as lecture and consulting fees from Astellas Pharma, Chiesi Farmaceutici SpA, Novartis Pharma, and Vifor Pharma. In the last 3 years, T.v.G. has received lecture fees and study grants from Chiesi and Astellas, 
in addition to consulting fees from Roche Diagnostics, Vitaeris, CSL Behring, Astellas, Aurinia Pharma, and Novartis. M.C.C.-v.G. received grant support from Astellas Pharma (paid to the Erasmus MC). All other authors declared no competing interests for this work.

\section{AUTHOR CONTRIBUTIONS}

M.I.F., B.C.M.d.W., and D.A.H., wrote the manuscript. L.M.A., T.v.G., B.vd.H., B.C.M.d.W., and D.A.H. designed the research. M.I.F., L.M.A., H.L.L., J.vd.W., M.C.C.v.G. B.C.M.d.W., R.H.N.v.S and D.A.H. performed the research. M.I.F. analyzed the data.

\section{DATA AVAILABILITY}

Data were collected in OpenClinica. The data that support the findings of this study are available from the corresponding author upon reasonable request.

(c) 2021 The Authors. Clinical Pharmacology \& Therapeutics published by Wiley Periodicals LLC on behalf of American Society for Clinical Pharmacology and Therapeutics.

This is an open access article under the terms of the Creative Commons Attribution-NonCommercial-NoDerivs License, which permits use and distribution in any medium, provided the original work is properly cited, the use is non-commercial and no modifications or adaptations are made.

1. Brunet, M. et al. Therapeutic drug monitoring of tacrolimuspersonalized therapy: second consensus report. Ther. Drug Monit. 41, 261-307 (2019).

2. Prograf, Summary of product characteristics (European Medicines Agency (2006) <https://www.ema.europa.eu/en/documents/refer ral/prograf-article-30-referral-annex-i-ii-iii_en.pdf>.

3. Kidney Disease: Improving Global Outcomes Transplant Working Group. KDIGO clinical practice guideline for the care of kidney transplant recipients. Am. J. Transplant. 9(suppl 3), S111-S155 (2009).

4. Andrews, L.M. et al. Overweight kidney transplant recipients are at risk of being overdosed following standard bodyweight-based tacrolimus starting dose. Transplant. Direct 3, e129 (2017).

5. Press, R.R. et al. Explaining variability in tacrolimus pharmacokinetics to optimize early exposure in adult kidney transplant recipients. Ther. Drug Monit. 31, 187-197 (2009).

6. Passey, C., Birnbaum, A.K., Brundage, R.C., Oetting, W.S., Israni, A.K. \& Jacobson, P.A. Dosing equation for tacrolimus using genetic variants and clinical factors. Br. J. Clin. Pharmacol. 72, 948-957 (2011).

7. Shuker, N. et al. A randomized controlled trial comparing the efficacy of Сyp3a5 genotype-based with body-weight-based tacrolimus dosing after living donor kidney transplantation. Am. J. Transplant. 16, 2085-2096 (2016).

8. Budde, K. et al. Novel once-daily extended-release tacrolimus (LCPT) versus twice-daily tacrolimus in de novo kidney transplants: one-year results of phase III, double-blind, randomized trial. Am. J. Transplant. 14, 2796-2806 (2014).

9. Thervet, E. et al. Optimization of initial tacrolimus dose using pharmacogenetic testing. Clin. Pharmacol. Ther. 87, 721-726 (2010).

10. Hesselink, D.A. \& Hoorn, E.J. Improving long-term outcomes of kidney transplantation: the pressure is on. Neth. J. Med. 72, 248250 (2014).

11. Andrews, L.M. et al. A population pharmacokinetic model to predict the individual starting dose of tacrolimus in adult renal transplant recipients. Br. J. Clin. Pharmacol. 85, 601-615 (2019).

12. Staatz, C.E. \& Tett, S.E. Clinical pharmacokinetics and pharmacodynamics of tacrolimus in solid organ transplantation. Clin. Pharmacokinet. 43, 623-653 (2004).

13. Storset, E., Holford, N., Midtvedt, K., Bremer, S., Bergan, S. \& Asberg, A. Importance of hematocrit for a tacrolimus target concentration strategy. Eur. J. Clin. Pharmacol. 70, 65-77 (2014).
14. Andrews, L.M. et al. Dosing algorithms for initiation of immunosuppressive drugs in solid organ transplant recipients. Expert Opin. Drug Metab. Toxicol. 11, 921-936 (2015).

15. Andreu, F. et al. A new CYP $3 A 5 * 3$ and CYP3A4*22 cluster influencing tacrolimus target concentrations: a population approach. Clin. Pharmacokinet. 56, 963-975 (2017).

16. Han, N. et al. Prediction of the tacrolimus population pharmacokinetic parameters according to CYP3A5 genotype and clinical factors using NONMEM in adult kidney transplant recipients. Eur. J. Clin. Pharmacol. 69, 53-63 (2013).

17. Bergmann, T.K., Hennig, S., Barraclough, K.A., Isbel, N.M. \& Staatz, C.E. Population pharmacokinetics of tacrolimus in adult kidney transplant patients: impact of CYP3A5 genotype on starting dose. Ther. Drug Monit. 36, 62-70 (2014).

18. Chen, S.Y. et al. Individualization of tacrolimus dosage basing on cytochrome $\mathrm{P} 4503 \mathrm{~A} 5$ polymorphism-a prospective, randomized, controlled study. Clin. Transplant. 27, E272-E281 (2013).

19. Golubovic, B., Vucicevic, K., Radivojevic, D., Kovacevic, S.V., Prostran, M. \& Miljkovic, B. Total plasma protein effect on tacrolimus elimination in kidney transplant patients-population pharmacokinetic approach. Eur. J. Pharm. Sci. 52, 34-40 (2014).

20. Zuo, X.C. et al. Effects of CYP3A4 and CYP3A5 polymorphisms on tacrolimus pharmacokinetics in Chinese adult renal transplant recipients: a population pharmacokinetic analysis. Pharmacogenet. Genomics 23, 251-261 (2013).

21. Asberg, A. et al. Inclusion of CYP3A5 genotyping in a nonparametric population model improves dosing of tacrolimus early after transplantation. Transpl. Int. 26, 1198-1207 (2013).

22. Antignac, M., Barrou, B., Farinotti, R., Lechat, P. \& Urien, S. Population pharmacokinetics and bioavailability of tacrolimus in kidney transplant patients. Br. J. Clin. Pharmacol. 64, 750-757 (2007).

23. Zhao, W. et al. Population pharmacokinetics and pharmacogenetics of tacrolimus in de novo pediatric kidney transplant recipients. Clin. Pharmacol. Ther. 86, 609-618 (2009).

24. Andrews, L.M. et al. A population pharmacokinetic model to predict the individual starting dose of tacrolimus following pediatric renal transplantation. Clin. Pharmacokinet. 57, 475-489 (2018).

25. Zhang, H.J., Li, D.Y., Zhu, H.J., Fang, Y. \& Liu, T.S. Tacrolimus population pharmacokinetics according to CYP3A5 genotype and clinical factors in Chinese adult kidney transplant recipients. $J$. Clin. Pharm. Ther. 42, 425-432 (2017).

26. Woillard, J.B. et al. Tacrolimus updated guidelines through popPK modeling: how to benefit more from CYP3A pre-emptive genotyping prior to kidney transplantation. Front. Pharmacol. 8 , 358 (2017).

27. Kirubakaran, R., Stocker, S.L., Hennig, S., Day, R.O. \& Carland, J.E. Population pharmacokinetic models of tacrolimus in adult transplant recipients: a systematic review. Clin. Pharmacokinet. 59(11), 1357-1392 (2020).

28. van Gelder, T. \& Hesselink, D.A. Dosing tacrolimus based on CYP3A5 genotype: will it improve clinical outcome? Clin. Pharmacol. Ther. 87, 640-641 (2010).

29. Boughton, O., Borgulya, G., Cecconi, M., Fredericks, S., MoretonClack, M. \& MacPhee, I.A. A published pharmacogenetic algorithm was poorly predictive of tacrolimus clearance in an independent cohort of renal transplant recipients. Br. J. Clin. Pharmacol. 76, 425-431 (2013).

30. Andrews, L.M. et al. A population pharmacokinetic model does not predict the optimal starting dose of tacrolimus in pediatric renal transplant recipients in a prospective study: lessons learned and model improvement. Clin. Pharmacokinet. 59(5), 591-603 (2020).

31. Loupy, A. et al. The Banff 2019 Kidney Meeting Report (I): updates on and clarification of criteria for T cell- and antibodymediated rejection. Am J Transplant 20(9), 2318-2331 (2020).

32. Levey, A.S. et al. A new equation to estimate glomerular filtration rate. Ann. Intern. Med. 150, 604-612 (2009).

33. Simon, R. Optimal two-stage designs for phase II clinical trials. Control. Clin. Trials 10, 1-10 (1989). 
34. R-CoreTeam. R: A language and environment for statistical computing. R Foundation for Statistical Computing, Vienna, Austria. <https://www.R-project.org/>.

35. Elens, L. et al. Impact of POR*28 on the pharmacokinetics of tacrolimus and cyclosporine A in renal transplant patients. Ther. Drug Monit. 36, 71-79 (2014).

36. Zhang, J.J., Zhang, H., Ding, X.L., Ma, S. \& Miao, L.Y. Effect of the P450 oxidoreductase 28 polymorphism on the pharmacokinetics of tacrolimus in Chinese healthy male volunteers. Eur. J. Clin. Pharmacol. 69, 807-812 (2013).

37. de Jonge, H., Metalidis, C., Naesens, M., Lambrechts, D. \& Kuypers, D.R. The P450 oxidoreductase *28 SNP is associated with low initial tacrolimus exposure and increased dose requirements in CYP3A5-expressing renal recipients. Pharmacogenomics 12, 1281-1291 (2011).

38. Heisel, O., Heisel, R., Balshaw, R. \& Keown, P. New onset diabetes mellitus in patients receiving calcineurin inhibitors: a systematic review and meta-analysis. Am. J. Transplant. 4, 583595 (2004).

39. Webster, A.C., Woodroffe, R.C., Taylor, R.S., Chapman, J.R. \& Craig, J.C. Tacrolimus versus ciclosporin as primary immunosuppression for kidney transplant recipients: meta-analysis and metaregression of randomised trial data. BMJ 331, 810 (2005).

40. Gaynor, J.J. et al. Lower tacrolimus trough levels are associated with subsequently higher acute rejection risk during the first 12 months after kidney transplantation. Transpl. Int. 29, 216-226 (2016).
41. US Food and Drug Administration (FDA). (2012). Prograf product information, Reference ID 3083402.

42. Storset, E. et al. Improved tacrolimus target concentration achievement using computerized dosing in renal transplant recipients-a prospective, randomized study. Transplantation 99, 2158-2166 (2015).

43. Ekberg, H. et al. Reduced exposure to calcineurin inhibitors in renal transplantation. N. Engl. J. Med. 357, 2562-2575 (2007).

44. Kuypers, D.R., Evenepoel, P., Maes, B., Coosemans, W., Pirenne, J. \& Vanrenterghem, Y. The use of an anti-CD25 monoclonal antibody and mycophenolate mofetil enables the use of a low-dose tacrolimus and early withdrawal of steroids in renal transplant recipients. Clin. Transplant. 17, 234-241 (2003).

45. Hesselink, D.A., Bouamar, R., Elens, L., van Schaik, R.H. \& van Gelder, T. The role of pharmacogenetics in the disposition of and response to tacrolimus in solid organ transplantation. Clin. Pharmacokinet. 53, 123-139 (2014).

46. Guo, Y. et al. Commensal gut bacteria convert the immunosuppressant tacrolimus to less potent metabolites. Drug Metab. Dispos. 47, 194-202 (2019).

47. Lee, J.R. et al. Gut microbiota and tacrolimus dosing in kidney transplantation. PLoS One 10, e0122399 (2015).

48. Zimmermann, M., Zimmermann-Kogadeeva, M., Wegmann, R. \& Goodman, A.L. Mapping human microbiome drug metabolism by gut bacteria and their genes. Nature 570, 462-467 (2019). 